\title{
The Effect of Poly vinyl chloride-co-vinyl acetate Crosslinking Agent on Mechanical Properties of Acrylic Primer for Concrete Substrate Application
}

\section{EL-SAYED NEGIM ${ }^{1,2 *}$, GALIYA S. IRMUKHAMETOVA ${ }^{3}$, LYAZZAT BEKBAYEVA ${ }^{4}$, AYAZHAN BEKBAYEVA ${ }^{5}$ and GRIGORIY A. MUN ${ }^{3}$}

${ }^{1}$ School of Chemical Engineering, Kazakh-British Technical University, 106 Walikhanov Street, Almaty, 050010, Kazakhstan.

${ }^{2}$ National Research Centre, Polymer \& Pigment Department, 33 El Bohouth St., Dokki, Giza 12622, Egypt.

${ }^{3}$ Department of Chemistry \& Technology of Organic Materials, Polymers and Natural Compounds,

${ }^{5}$ Faculty of Biology and Biotechnology, al Faraby Kazakh National University, 71, al-Faraby av., 050040, Almaty, Kazakhstan.

${ }^{4}$ Kazakh National Research Technical University named after K.I. Satpayev, 22 Satpayev Street, 050013 Almaty, Kazakhstan.

${ }^{*}$ Corresponding author E-mail: elashmawi5@yahoo.com

http://dx.doi.org/10.13005/ojc/340126

(Received: October 30, 2017; Accepted: November 20, 2017)

\begin{abstract}
Effect of addition 0.5 and $1 \%$ of poly vinyl chloride-co-vinyl acetate (PVCV) as crosslinking agent to acrylic syrup on mechanical properties of primer was studied. Acrylic syrup made from a methyl methacrylate monomer solution of terpolymers. Terpolymers were used based on methyl methacrylate, 2-ethylhexyl acrylate and methacrylic acid. Mechanical properties including pot-life, tensile strength, elongation, water absorption, contact angle and bond strength were investigated. The results showed that the addition of PVCV to acrylic syrup improved the mechanical properties of primer due to the presence of carbon-chlorine bonds which produce the dispersion forces. However, as the concentration of PVCV increases, the mechanical properties of primer increases. The primer syrup containing 65\% 2-ethylhexyl acrylate and $1.0 \%$ PVCV has good bonding strength with concrete substrate around $2.05 \mathrm{MPa}$.
\end{abstract}

Keywords: Acrylic syrup, methyl methacrylate, primer, poly vinyl chloride-co-vinyl acetate. 


\section{INTRODUCTION}

The acrylic resin Poly (methyl methacrylate) (PMMA) is used almost universally for surface coatings, adhesives, concrete, aircraft windows and thick polymer sheets ${ }^{1-4}$. PMMA has been continuously developed and gained an important role in industrial applications ${ }^{4-6}$. A number of researchers have distinguished chemical modification of PMMA through bulk polymerization of MMA with different kinds of vinyl monomers ${ }^{5,7-10}$. Poly (methyl methacrlate-co-Butyl methacrylate) was prepared by bulk polymerization in presence of azobisisobutyronitrile as an initiator and confirmed the structure by using Fourier transform infrared spectroscopy. The obtained copolymers were investigated via TGA, DSC and SEM. The results showed that, the physical and mechanical properties of copolymer increased with increasing the ratio of MMA in the copolymer ${ }^{11}$. The Poly (methyl methacrylate-co-styrene) was prepared by bulk polymerization in presence of tetraphenyl bisphosphine as initiator. The yield of polymerization was up to $15 \%$ for polystyrene and up to $62 \%$ for PMMA ${ }^{12}$. Negim at el., ${ }^{13}$ studied physico-mechanical properties of acryl syrups which are made from poly (methyl methacrlate-co-Butyl methacrylate) and MMA monomer. The effect of copolymer powder to MMA- monomer ratio on the physico-mechanical properties acryl syrup mixes for paint applications was investigated. Testing included pot-life, curing time, viscosity, tensile strength, elongation, water absorption and hardness shore $\mathrm{A}$. The results showed that, not only monomer composition of the copolymer but also the ratio of copolymer to MMAmonomer affected the physico-mechanical properties of acrylic films. The tensile strength, hardness, pot-life, curing time and hardness of the acrylic film increased with the increase of the MMA ratio in copolymer and decrease content of copolymer in acrylic syrup mixes. The physical and mechanical properties of acrylic primer containing acryl syrup and benzoyl peroxide as an initiator were investigated ${ }^{14}$. Acryl syrup consists of Poly (methyl methacrylate-co-2-ethylhexyacrylate-comethacrylic acid) and MMA monomer. The results showed that, increasing the amount of MMA in terpolymer backbone, increased tensile and contact angle of primer films while elongation at break, water absorption and bond strength are decreased. In particular, the primer syrup containing $65 \%$ 2-ethylhexylacrylate have good bonding strength with concrete substrate around 1.1 MPa. In the present work acryl syrups consist of Poly(methyl methacrylate-co-2-ethylhexyacrylate-co-methacrylic acid), MMA monomer and poly(vinyl chloride-covinyl acetate) and the effect of poly(vinyl chlorideco-vinyl acetate) as crosslinking agent on the physico-mechanical properties of primer for concrete substrate application.

\section{EXPERIMENTAL}

\section{Materials}

Methyl methacrylate (MMA), 2-ethyl hexyl acrylate (2-EHA), methacrylic acid (MAA) monomers, 2,2'-azobis (2-methylpropionitrile) AIBN (initiator), poly (vinyl chloride-co-vinyl acetate) (PVCV), solvents (ethanol and diethyl ether), N, Ndimethyl-p-toluidine (NDPT), benzoyl peroxide (BPO), sodium hydroxide $(1 \mathrm{~N})$ were purchased from Fluka.

\section{Synthesis and characterization of terpolymers}

Terpolymerization of MMA, 2-EHA and MAA monomers were carried out by using bulk polymerization techniques at various monomers ratios (M1=65: 30: 5) wt.\%, (M2= 75: 20: 5) wt. \%, and (M3=80: 15: 5) wt. \%, respectively using ABIN as an initiator. The preparation of terpolymers and the methods of analysis (FTIR, ${ }^{1} \mathrm{H}$ NMR, TGA, DSC and SEM) have been previously described in a previous investigation ${ }^{14}$.

\section{Primer film formation:}

Primer syrups were produced by dissolving terpolymers powder (M1, M2 and M3) into MMA monomer at normal temperature $\left(25^{\circ} \mathrm{C}\right)$ to maintain the primer syrup at $15 \%$, respectively. The viscosity of the primer syrups increases noticeably in few minutes due to partial dissolution of particles of terpolymers, in addition to the conversion of the monomeric MMA into polymer chain ${ }^{8,11,12}$. In mixes $\mathrm{M} 1, \mathrm{M} 2$, and $\mathrm{M} 3,0.5$ and $1.0 \%$ of PVCV were added respectively. Then, primer films (M1, M2 and M3) were prepared by casting the primer syrup after mixing with initiator BPO and accelerator NDPT, which was added at 2.0 part and 1.0 part per hundred (pph) of terpolymers to mixtures respectively, on leveled surfaces and allowing them to dry to dry at $60^{\circ} \mathrm{C}$, for 2 hours. 


\section{Measurements}

Pot-life and cure time tests were according to DIN EN ISO $9514^{15}$ and ASTM D5895-03 ${ }^{16}$, respectively. Pot-life and curing time measured by mixing $100 \mathrm{~g}$ of primer syrups with BPO and NDPT in a small container at room temperature $25^{\circ} \mathrm{C}$. Timing begins when start mixing and ends when the material become gels is pot-life time and ends when materials become completely drying is called cure time. The tensile properties of the terpolymer cast films were measured by using MTS 10/M tensile testing machine at a crosshead speed of $50 \mathrm{~mm} /$ $\min$. The tensile test specimen is made in the shape of a "dog bone" and fixed into clamps on a machine that will pull it apart from each end. This test continues until a fracture appears. An average of at least four measurements was taken, and the 1-kN load cell was used. Shore D hardness was measured using an indentation hardness tester according to ASTM D2240-75. Dynamic wetting tests were performed on a Camtel CDCA-100F dynamic adsorption apparatus (Camtel, UK). Each sample was cut to a size of $1 \mathrm{~cm} \times 5 \mathrm{~cm}$ with sharp scissors. When the specimen was immersed into water for 6 months, the weight of adsorbed water was detected and recorded. The dynamic water adsorption was plotted as a function of feed composition of monomers. A universal Testing Machine (DCS-500, Shimadzu Crop, Kyoto, Japan) at a crosshead speed of $0.5 \mathrm{~mm} / \mathrm{min}$., was used to conduct the bond strength test ${ }^{17-23}$. The calculated bond strength was determined by dividing the force at which bond failure occurred by the bonding area.

\section{RESULTS AND DISCUSSION}

\section{Structure of terpolymers}

The structure of terpolymer based on MMA, 2-EHA and MAA is shown in Scheme 1. Terpolymers in three different ratios 30: 65: 5 (M1), 47.5: 47.5: 5 (M2) and 65: 30: 5 (M3) were prepared in presence of $\mathrm{ABIN}$ as an initiator using a free radical technique. Acrylic syrups were prepared with 15 wt.\% terpolymer and 85 wt.\% MMA monomer and used as primer for concrete substrate. The pysicomechanical properties of primer have been previously reported by Negim et al., ${ }^{14}$ the results showed that the properties of primer increased with increasing the amount of MMA in terpolymer backbone. However, the best terpolymer composition, which produces primer with good bond strength with concrete substrate, was 65 wt.\% of 2-EHA.

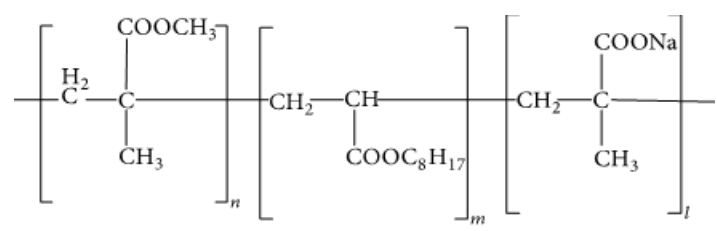

Scheme 1: Structure of the terpolymer, Negim et al., ${ }^{14}$

\section{Characterization of primer films.}

Pot-life is the amount of time it takes for an initial mixed viscosity to double, or quadruple for lower viscosity and will not change within an application. Pot-life of primer syrups (M1, M2, M3) mixed with different ratios of PVCV $(0.5 \& 1.0 \%)$ as crosslinking agent is shown in Fig. 1. The pot-life of primer syrups varied from 9 to $30 \mathrm{~min}$. for $0.5 \%$ PVCV and from 3 to 19 for $1.0 \%$ PVCV with increasing the content of MMA in the primer syrups from 65 to $80 \mathrm{wt} \%$. As expected, and in agreement with previously reported results by other authors ${ }^{14}$, pot-life decreases with increasing MMA. However, pot-life of primer syrup decreased sharply with increasing PVCV from 0.5 to $1.0 \%$. Pot-life can act as a guide in determining cure time of primer syrups by providing a rough timeline of viscosity growth.

Figure. 2 shows the effect of PVCV content on the curing time of primer syrups at room temperature. The curing time decreased as the MMA content increased in primer syrups. However, a shortest curing time was obtained when added $1.0 \% \mathrm{PVCV}$ to primer syrups. The shortest curing time was due to crosslinking agent of PVCV. In general, pot-life and cure time of primer syrups depend on many factors such as catalysis, temperatures and crosslinking agent ${ }^{24,25,26,27}$.

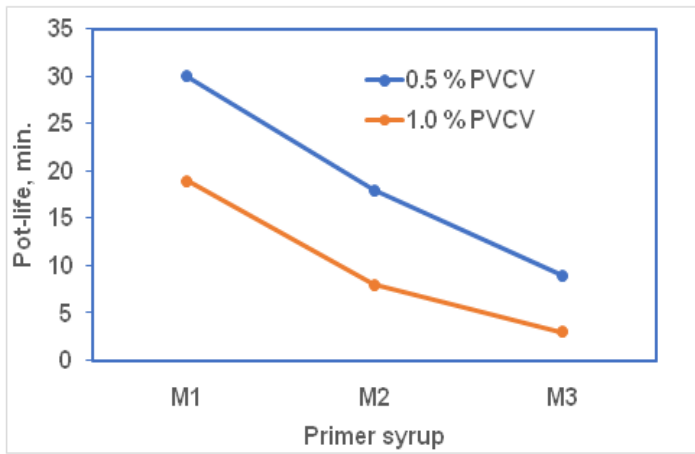

Fig. 1. Pot-life of primer syrup in presence of PVCV as crosslinking agent. 


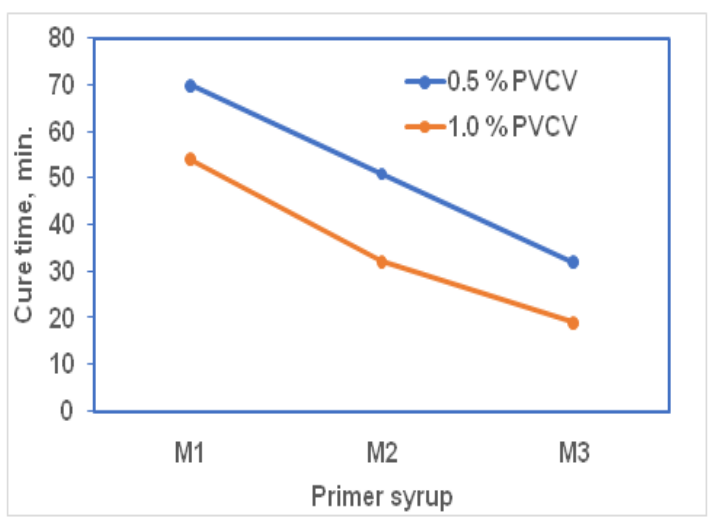

Fig. 2. Cure time of primer syrup in presence of PVCV as crosslinking agent

Contact angle measured by producing a drop of liquid on the surface of dried primer film. Contact angle measurement of films provides more information of wettability, hydrophilicity and hydrophobicity of a surface of dried film. For example, a drop of liquid with a contact angle more than $90^{\circ}$ is hydrophobic and a drop with contact angle less than $90^{\circ}$ is hydrophilic ${ }^{28}$. The effect of crosslinking content (PVCV) on the contact angle of dried primer films is shown in Fig. 3. The contact angle increased as the content of MMA increased from 65 to $80 \mathrm{wt} \%$ as in the study reported in reference ${ }^{14}$. However, contact angle of dried film primer increased with the addition of PVCV to primer syrups as crosslinking agent. Furthermore, contact angle of film primer in presence of $1.0 \% \mathrm{PVCV}$ was more than that in case of $0.5 \%$ PVCV. It can be seen in the Fig. 3 that the contact angle of primer films is more than $90^{\circ}$, means that, the surface of primer films is poor wetting, hydrophobic and completely drying.

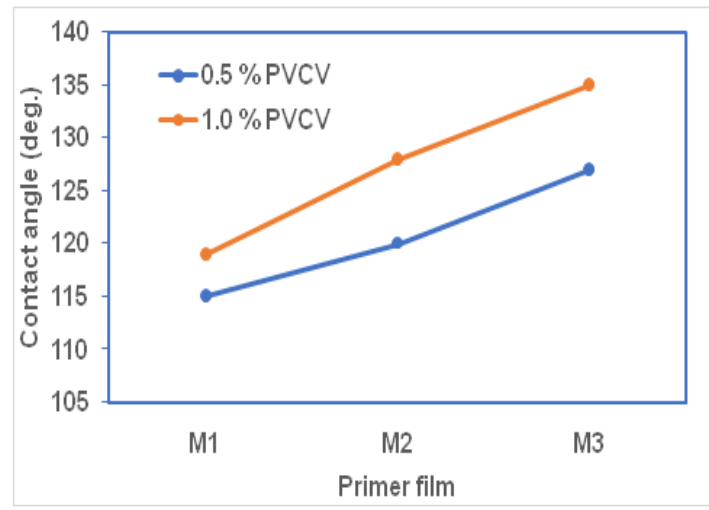

Fig. 3. Contact angle of primer syrup in presence of PVCV as crosslinking agent

Table. 1 shows the effect of PVCV content on the mechanical properties of film primers. As shown in this Table, with increasing MMA content in primer syrups, mechanical properties including tensile strength, hardness increased and elongation at break decreased. From Table. 1, it was observed that tensile strength and hardness increased with increases in PVCV content. For polymers, it is known that the mechanical properties are sensitive to the crosslinking content ${ }^{29}$. Primer syrups mixed with $1.0 \%$ PVCV gave the highest tensile strength $\left(405.1 \mathrm{kgf} / \mathrm{cm}^{2}\right)$ and hardness (90) (M3) while primer syrup mixed with $0.5 \%$ PVCV showed tensile strength (350.8 kgf/cm ${ }^{2}$ ) and hardness (85) M3. The increase in mechanical properties is attributed to crosslink between PVCV and terpolymer due to the formation of a long side chain and formation network crosslinking films. The same behavior was reported by Vakil and Martin ${ }^{30}$ when they studied the effect of crosslinking agent on the physical and mechanical properties of epoxies.

Table. 1. Mechanical properties of the primer cast films in presence of PVCV as crosslinking agent.

$\begin{array}{ll}\text { Crosslinking concentration } & \text { PVCV, \% }\end{array}$

\begin{tabular}{lcccccc}
\hline & 0.5 & 1.0 & 0.5 & 1.0 & 05 & 1.0 \\
Samples & M1 & M2 & M3 & & & \\
Tensile strength $\left(\mathrm{kgf} / \mathrm{cm}^{2}\right)$ & 199.6 & 216.9 & 287.4 & 319.3 & 350.8 & 405.1 \\
Elongation (\%) & 50.2 & 44.9 & 30.4 & 20.7 & 5.1 & 0.0 \\
Hardness (shore D) & 75 & 81 & 79 & 88 & 85 & 90 \\
\hline
\end{tabular}

Adhesion of the primer is importance for success of painting process of concrete substrate.
For example, concrete is very porous and will absorb the solvent from paint and drying the paint 
prematurely. Fig. 4, shows the effect of PVCV content on the adhesion strength between primer syrup and concrete substrate. The results showed that sharp increase in the bond strength with increasing 2-EHA in primer syrups. However, the bond strength between primer and concrete substrate increased with addition of PVCV as crosslinking agent. From Fig. 4, it can be seen that the surface layer of primer mixed with PVCV exhibits excellent adhesion to the concrete substrate. This is attributed to the role of $\mathrm{C}-\mathrm{Cl}$ bond in PVCV is to provide good surface adhesion and crosslinking with concrete substrate. Further more, an increase in bond strength with increasing the PVCV content in the primer syrups. As expected and in agreement with previously reported results by other authors ${ }^{31}$.

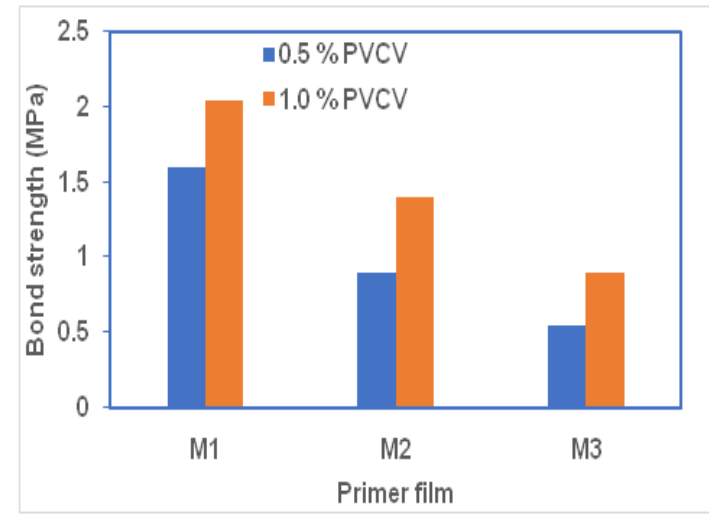

Fig. 4. Bond strength of primer syrup in presence of PVCV as crosslinking agent

\section{CONCLUSIONS}

The mechanical properties of primer films containing acryl syrups and PVCV as crosslinking agent were investigated. Acryl syrups were terpolymer of MMA, 2-EHA and MMA in three different ratios, about 30: 65: 5, 47.5: 47.5: 5, and 65: 30: 5, respectively. Based on the experimental results, the following occlusions can be drawn:

1. Incorporating PVCV as a crosslinking agent increases pot-life, curing time, tensile strength, hardness, contact angle and bond strength between primer and concrete substrate and decreases elongation at break.

2. Increasing the PVCV content in primer syrups, increasing mechanical properties of the primer due to the role of $\mathrm{C}-\mathrm{Cl}$ bond in $\mathrm{PVCV}$ is to provide crosslinking and network structure films.

3. Contact angle of film primers are more than $90^{\circ}$ and films are hydrophobic.

4. The primer showed excellent adhesion with addition of PVCV to primer syrups as crosslinking, especially primer containing 65 wt.\% 2-EHA and 1.0 wt.\% PVCV.

\section{ACKNOWLEDGMENTS}

The work was financially supported by Ministry of Science and Education of the Republic of Kazakhstan, Project no. 0115PK01660.

\section{REFERENCES}

1. Hamizah, A.S.; Mariatti, J. Polymer-Plastic Technology and Engineering, 2009, 48, 554-560.

2. Silikas, N.; Al-Kheraif, A.; Watts, D.C. Biomaterials 2005, 26, 197-204.

3. Tylman, S.; Peyton, F. Acrylics and Other Synthetic Resins Used in Dentistry, Philadelphia, PA: Lippincott, 1946, 2590.

4. Negim, E.S.M.; Aisha, A.M.B.; Yessimkanova, U.; Kurmanbekova, A.; Tyazhina, K.; Urkimbaeva, P.I.; Rakhmetullayeva, R.K.; Shatabayeva, E.; Irmukhametova, G.; Mun G.A.; Yeligbayeva, G.Zh.; Khatib, J.M. International Journal of Basic and Applied Sciences, 2015, 4, 10-18.

5. Vijayanand, P.S.; Jone, S.; Penlidis, C.S.; Nanjundan, A.S. Polymer International.,
2003, 52, 1856-1862.

6. Balke, S.T.; Hamielec, A.E. J. Appl. Polym. Sci.,1973, 17, 905-949.

7. Ramaseshan, V.; Trivedi, M.K.; Raghunathan, T.S. Polym. Int. 1993, 32, 275-281.

8. Zhou, F.; Gupta, S.K.; Ray A.K. J. Appl. Polym. Sci. 2001, 81, 1951-1971.

9. Peyser, P.; Brandrup J.; Immergut, E.H. Eds. Polymer Handbook, $3^{\text {rd }}$ ed. Wiley-Inter science, New York., 1989, VI, 219.

10. Clemens, A.; Reimund S. Polymer Bulletin, 1993, 30, 257-264.

11. Aisha, N.; Mussylmanbek, S.; Negim, E.S.; Ergali, R.; Assem, S. Int. J. Chem. Sci., 2015, 13, 922-934. 
12. Ida, P.; Anton, S. Macromoleculare Chemistry and Physics 1999, 200, 2088-2099.

13. Negim, E.S.M.; Nurlybayeva, A.;Irmukhametova, G.S.; Makhatova, A.; Basharimova, A.; Serikkali, A.; Sakhy, M.; Iskakov, R.; Mun G.A. International Journal of Biology and Chemistry, 2015, 8, 60-65.

14. Negim, E.S.; Nurlybayeva, A.; Grigoriy, A.M.; Rinat, I.; Galiya, S.I.; Mussylmanbek, S. International Journal of Polymer Science, 2016, 2016, 1-9.

15. DIN EN ISO 9514. Test the pot-life of liquid systems., 1994.

16. ASTM D5895-03: Standard Test Methods for Evaluating Drying or Curing During Film Formation of Organic Coatings Using Mechanical Recorders., 1994.

17. Chang, P.P.; Hansen, N.A.; Phoenix, R.D.; Schneid, T.R. J. Prosthodont., 2009, 18, 23-31.

18. Frangou, M.J.; Polyzois, G.L.; Tarantili, P.A.; Andreopoulos, A.G. Eur J Prosthodont Restor, Dent., 2003, 11, 115-118.

19. Hatamleh, M.M.; Watts, D.C. Dent Mater., 2010, 26, 387-395.

20. Polyzois, G.L. Int. J. Prosthodont., 1996, 5,101-104.

21. Polyzois, G.L.; Frangou, M.J.; Andreopoulos, A.G. Int. J. Prosthodont., 1991, 4, 440-444.
22. Stamatacos, M.C.; Hottel, T.L. Am J Dent., 2005, 18, 105-108.

23. Taft, R.M.; Cameron, S.M.; Knudson, R.C.; Runyan, D.A. J. Prosthet Dent. 1996, 76, 515-518.

24. Negim E.S.; Niyazbekova, R.; Bekbayeva, L.; Utelbayeva, A.; Bengin, M.H.; Nursultanov, M.; Iskakov, R.; Yeligbayeva, G. Orient. J. Chem., 2017, 33(1), 450-457.

25. Syrmanova, K.; Negim, E.; Kaldybekoekova, J.; Tuleuov, A.M. Orient. J.Chemi., 2016, 3(2), 1-7.

26. Ayoub, M.M.H.; El-Awady, M.M.; Nasr, H.E.; Negim, S.M. J. Polymer-Plastics Technology and Engineering 2003, 42, 863-881.

27. Ayoub, M.M.H.; Nasr, H.E.; Darweesh, M.H.H.; Negim, S.M. J. Polymer-Plastics Technology and Engineering 2005, 44, 305-319.

28. Negim, S.M.; Bahruddin, S.; Mahyuddin, R.; Idiris, M.S. J. Applied Polymer Science 2011, 121, 8-13.

29. Wang, S.; Yaszemski, M.J.; Gruetzmacher, J.A.; Lu, L. Polymer 2008, 49, 5692-5699.

30. Vakil, U.M.; Martin, G.C. Journal of Applied Polymer Science, 1992, 46, 2089-2099.

31. Neslihan, A.; Bunyamin, K.; Tuncer, E.A.; Niyazi, B. Progress in Organic Coatings, 2007, 60, 69-74. 